\title{
Vira e mexe nacionalismo
}

Álvaro Silveira Faleiros ${ }^{1}$

PERRONE-MOISÉS, Leyla. Vira e mexe nacionalismo: paradoxos do nacionalismo literário. São Paulo: Companhia das Letras, 2007.

Ao colocar como subtítulo de sua mais nova e iluminadora coletânea de textos, os "paradoxos do nacionalismo literário", Leyla Perrone-Moisés define com clareza o fio que guia sua reflexão ao longo dos quatorze artigos que compõem o livro. Refletir sobre as tensões que permeiam a idéia de nação, assim como os conceitos de cultura, identidade, alteridade e colonialismo que lhe são correlatos, por meio da literatura, justifica-se, para a autora, pelo fato de que "as obras literárias esclarecem, tanto ou mais do que os discursos políticos, como são construídos os conceitos de nação e de identidade nacional".

Leyla Perrone-Moisés, mais do que refazer a história desses conceitos, trata de alguns dos paradoxos característicos da identidade nacional na América Latina e no Brasil e de como são problematizados sobretudo em obras literárias de autores ibero-americanos. No primeiro artigo, "A cultura latino-americana, entre a globalização e folclore", ela atenta para o fato de que a vontade de construção de uma identidade latino-americana pode levar a enganos, como o nacionalismo exacerbado, o populismo e o que chama de espontaneísmo. O nacionalismo exacerbado equivoca-se, pois reduz a cultura a uma suposta origem, o que limitaria a cultura latinoamericana às culturas indígenas ou às heranças africanas. $\mathrm{O}$ populismo, por sua vez, é de natureza paternalista e, ao cultuar o folclore, impede as culturas de inovar e as camadas populares de receber informações mais complexas; as manifestações culturais só são, nesse caso, apreendidas no que têm de pitoresco e exótico. O espontaneísmo é também um discurso redutor, pois, em nome da espontaneidade, da alegria e da afetividade características imputadas à parte sul do continente -, recusa-se o experimentalismo e o rigor artístico latino-americano. Todas essas concepções

1 Professor do Departamento de Letras Modernas da Faculdade de Filosofia, Letras e Ciências Humanas da Universidade de São Paulo. 
estão, de alguma forma, vinculadas à relação "filial, edipiana, com a Europa", de onde provém, inclusive, a própria noção de nacionalismo.

Como já havia indicado desde 1982, em seu artigo "Literatura comparada, intertextualidade e antropofagia", Leyla Perrone-Moisés sublinha mais uma vez a capacidade criativa e própria de se tratar com o paradoxo da herança européia, de autores como Jorge Luís Borges e sua concepção de patrimônio universal latino-americano, como José Lezama Lima e seu conceito de "protoplasma incorporativo", ou ainda como Oswald de Andrade e sua antropofagia cultural. Essas formas de "receptividade crítica e criadora" apontam para a necessidade e a existência de um discurso crítico latino-americano para o qual constantemente contribui. Ela comenta ainda que, "num mundo globalizado, essa capacidade de incorporação, e sobretudo de prefiguração, é um modelo que podemos oferecer às outras culturas".

A "prefiguração" é também central para se compreender como opera criticamente Leyla Perrone-Moisés. Em "Castro Alves e o aplicativo Victor Hugo", ao estabelecer relações entre os autores, ela desenvolve a noção de confluência. Além da influência e da aclimatação de Victor Hugo por Castro Alves, o poeta brasileiro "às vezes prefigura os procedimentos hugoanos" (grifo da autora), ou seja, há semelhanças entre os autores, coincidências que "não tem anterioridade temporal como prova".

Esse fenômeno de prefiguração, que chama de confluência, é um dos modos como Leyla Perrone-Moisés pensa a intertextualidade: um modo de reinterpretar, renovar, mediar. Assim, rompe-se com a lógica da influência, como na análise que ela faz em "Lautréamont e as margens americanas". Neste artigo, a autora aponta a dupla origem cultural de Isidore Ducasse e de como ela foi, primeiramente, negligenciada e, em seguida, exotizada por estudiosos. Foi seu trabalho desenvolvido com o crítico uruguaio Emir Rodríguez Monegal, publicado a partir de 1983, que evidenciou as marcas do bilingüismo e do bicultualismo nos Cantos de Maldoror, que vão desde a influência do barroco espanhol até os hispanismos que introduziu no léxico e na sintaxe de seus textos escritos em francês. Os efeitos literários dessas incorreções seriam, em parte, responsáveis por expressões originais cunhadas por Lautréamont; o que faria de seu handicap uma "vantagem estética”. Leyla Perrone-Moisés propõem, pois, pensar-se a relação entre a dupla cultura, hispano-americana e européia, de Lautréamont numa lógica avessa à influência.

A desestabilização da relação filial entre velho e novo mundo, produzida por Perrone-Moisés, dialoga com o conceito de "imagem dialética" de Walter Benjamin. Conceito que ela atualiza num dos mais brilhantes e reveladores artigos do livro, intitulado "Passagens: Isidore Ducasse, Walter Benjamin e Júlio Cortázar". A autora parte do conto "El outro cielo" de 
Cortázar, no qual a personagem se desloca no tempo e no espaço, indo de uma rua de luxo coberta (chamada à época de "passagem") da Buenos Aires dos anos 1940 para uma outra "passagem", em Paris, nos últimos dias do Segundo Império (1870), e estabelece uma relação deste conto com o Livro das passagens de Walter Benjamin, recentemente traduzido no Brasil.

Tendo como ponto de partida justamente as passagens parisienses, Benjamin desenvolve, nesse livro, um "novo método dialético da historiografia" que consiste em "atravessar o passado com a intensidade de um sonho, a fim de experimentar o presente como o mundo da vigília, ao qual o sonho se refere". Isto pressupõe seu novo conceito de "imagem dialética", que consiste, por sua vez, em lançar sobre o passado um olhar, tendo, como contraponto, o futuro daquele passado. Assim, seria possível compreender o presente "à luz daquilo que se anunciava (e se preparava) no ventre do passado".

Perrone-Moisés vê, no conto de Cortázar, a realização mais completa da imagem dialética de Benjamin. Nele, as imagens são duplicadas e, se por um lado, anulam a idéia de progresso, por outro, não reduzem o gesto do futuro à mera repetição do passado. Dessa maneira, ao atualizar o passado, o presente (futuro do passado) se constitui dialeticamente como síntese, realiza-se como um momento novo e inesperado. A autora destaca ainda que o maior interesse das imagens dialéticas para a literatura é o fato de que Benjamin declara que as mesmas se encontram na linguagem; nas suas palavras: "só as imagens dialéticas são imagens autênticas (isto é, não arcaicas); e o lugar onde as encontramos é a linguagem”.

Em seguida, a autora identifica a personagem do conto de Cortázar a Isidore Ducasse e retoma sua reflexão sobre o modo como Lautréamont produz imagens dialéticas da colonização atualizando, por exemplo, o passado barroco e Homero como invenção. Em sua conclusão, lança luz sobre o papel vital das imagens no processo de construção do saber, como revelação. Ela aponta, também, para a "função organizadora" da obra literária sem, contudo, perder de vista que a força revolucionária da literatura está não em introduzir conteúdo revolucionário numa obra, mas, sim, em desenvolver formas literárias com potencial revolucionário, como é o caso de Cortázar.

Situar com mais clareza a natureza específica do objeto literário por meio do conceito de imagem (imagens dialéticas, prefiguração) permite a Leyla Perrone-Moisés apontar alguns caminhos profícuos para uma crítica literária capaz de lidar com a complexidade e o caráter híbrido da literatura pós-colonial. $\mathrm{O}$ conceito de imagem serve também para uma melhor compreensão de alguns dos "Paradoxos do nacionalismo literário na América Latina", como se pode notar no artigo assim intitulado. 
Nele, a autora parte do princípio de que "a nação é um conjunto de imagens" e identifica uma série de metáforas sobre a América, surgidas logo após o Descobrimento, como a oposição entre a "velha Europa" e a "nova América" ou, ainda, "a tópica do americanismo como desterro" - discurso que vai dos primeiros letrados até Jorge Luís Borges e Sérgio Buarque de Holanda. Em seguida, outras metáforas ganham força, derivadas da primeira, como as oposições entre civilização e barbárie, aldeia e mundo, centro e periferia; sempre numa atitude depreciativa em relação à América. Essas tentativas de definição, como o nacionalismo, desembocaram em paradoxos, devido à inevitável origem européia tanto das línguas como da idéia mesmo de nação. Uma vez mais, Perrone-Moisés aponta, como superação, as propostas inclusivas de autores como Oswald de Andrade, Borges, Octavio Paz e Sábato.

Em outros artigos, acrescenta à lista Machado de Assis e Mário de Andrade. Retomando Gilberto Pinheiro Passos, nota, no primeiro, a presença de uma "poética diplomática" por meio da qual Machado lida ironicamente com a questão da nacionalidade, deixando-a em aberto, "porque esta é reconhecida como uma representação imaginária”. Mário de Andrade, por sua vez, é considerado pela autora como aquele que criou, no modernismo, “a obra máxima dedicada a essa questão [o nacionalismo]; diferentemente de Oswald, que ela define como autor da astuciosa e sugestiva metáfora antropofágica, mesmo se "não foi um pensador consistente". Leyla Perrone-Moisés assinala o uso do termo "entidade"ao invés de "identidade" por Mário de Andrade, evitando o essencialismo e a busca de uma origem que este último termo pressupõe. Mário trata, assim, do sujeito de cultura como um sujeito sempre em formação e em devir.

Dessa maneira, a autora coloca a discussão da formação das nações e de suas literaturas em relação a sua dimensão simbólica, por meio das metáforas. Não se trata, pois, de "fazer coincidir a autonomia literária com a autonomia política da nação", mas de compreender os paradoxos da literatura ibero-americana em função das imagens que cria de si mesma. $\mathrm{O}$ modo como se constituem as figurações preparam e anunciam prefigurações. As imagens constituídas, porém, não se estabilizam, mas estão em formação e são sempre negociadas.

Sua atitude reflexiva, contrária a qualquer dogmatismo e essencialismo, a leva, em dois outros artigos, a discutir os rumos dos estudos culturais e pós-coloniais. Em um deles, procura "desconstruir os estudos póscoloniais", mostrando como desvirtuam o pensamento derridiano ao tratar de forma essencialista as questões referentes à mulher, à raça e à periferia. Perrone-Moisés lembra que Derrida não trabalha com oposições e sim com descentramento, que para o filósofo francês não se trata de opor as margens 
ao centro, pois "as margens não tem centro único". Isso não significa que ele seja um relativista, uma vez que sua relação com a tradição - acrescenta a autora - é complexa e que é a partir de um profundo conhecimento dela que ele almeja desconstruí-la. A autora assinala a presença de aporias no pensamento derridiano e destaca o fato de a desconstrução ser uma prática filosófica e acadêmica, não política. Ela não visa, contudo, apontar possíveis limites e contradições desse pensamento identificados, por exemplo, por autores como Richard Freadman e Seumas Miller (RE-pensando a teoria, Unesp, 1994), para os quais o construtivismo lingüístico pós-saussureano de Derrida é, em grande medida, anti-humanista.

Em outro artigo, ela apresenta justamente o pensamento de Edward Said, que define como "um intelectual fora de lugar", chamando-o, em tom elogioso, de "humanista". Segundo a autora, Said, em Orientalismo (1979), antecipou os estudos culturais norte-americanos e os estudos pós-coloniais, mas, diferentemente da "impostação freqüentemente raivosa, simplificadora e demagógica de boa parte da produção teórico-crítica pós-colonial subseqüente", Said não adota atitude arrogante e procura "encarar os problemas de vários ângulos". Sua postura, com efeito, se aproxima daquela adotada por Leyla Perrone-Moisés, pois ambos recusam "tanto o determinismo historicista quanto 'a despreocupação etérea da crítica pós-axiológica' da chamada pós-modernidade" e, se lidam com os condicionamentos históricos e geográficos da obra literária, é sempre por meio da avaliação estética e da singularidade desta com as imagens que produz.

Enfim, essa breve resenha é mera introdução, pois nenhuma síntese será capaz de reproduzir a riqueza das análises contidas nesses quatorze brilhantes artigos, dos quais apenas comentamos alguns. Por isso, é imprescindível lê-la para entender, de fato, o alcance de suas reflexões. 